\title{
PROLEGOMENON TO THE THOUGHT STYLE OF THE NEW HISTORY OF PSYCHOLOGY
}

ANDRZEJ PANKALLA *

Adam Mickiewicz University, Poland

ALEKSANDRA KILIAN

University of East London, United Kingdom

ABSTRACT

The present article provides an introduction to the new history of psychology within the framework of critical perspective while offering some methodological solutions for contemporary historical research in psychology. We propose a new model of research for conducting studies in the history of psychology. This approach is predominantly concerned with reconstructing crypto thought styles, acknowledging the existence of peripheral sources of knowledge about human psychological life, and revealing hidden lines of inquiry, which will be presented using a contextual approach to the history of psychology. In this analysis, psychological knowledge will be treated as a product of social activities that occur under specific historical conditions and define the scope of psychological research. The proposed to examine history of psychology and investigative practice in a specific context will allow for deeper insight into the world's history of psychology and provide new methods for studying psychological schools of thought and ideas established on the periphery of mainstream psychology. Finally, we offer words of encouragement for scholars engaging in a context-specific study of psychological thought and efforts made towards grasping the reality of a local soul.
NEW HISTORY OF PSYCHOLOGY

CRITICAL PSYCHOLOGY

CRYPTO THOUGHT STYLE

REAL PSYCHOLOGY

PSYCHOLOGICAL ANTHROPOLOGY

눌

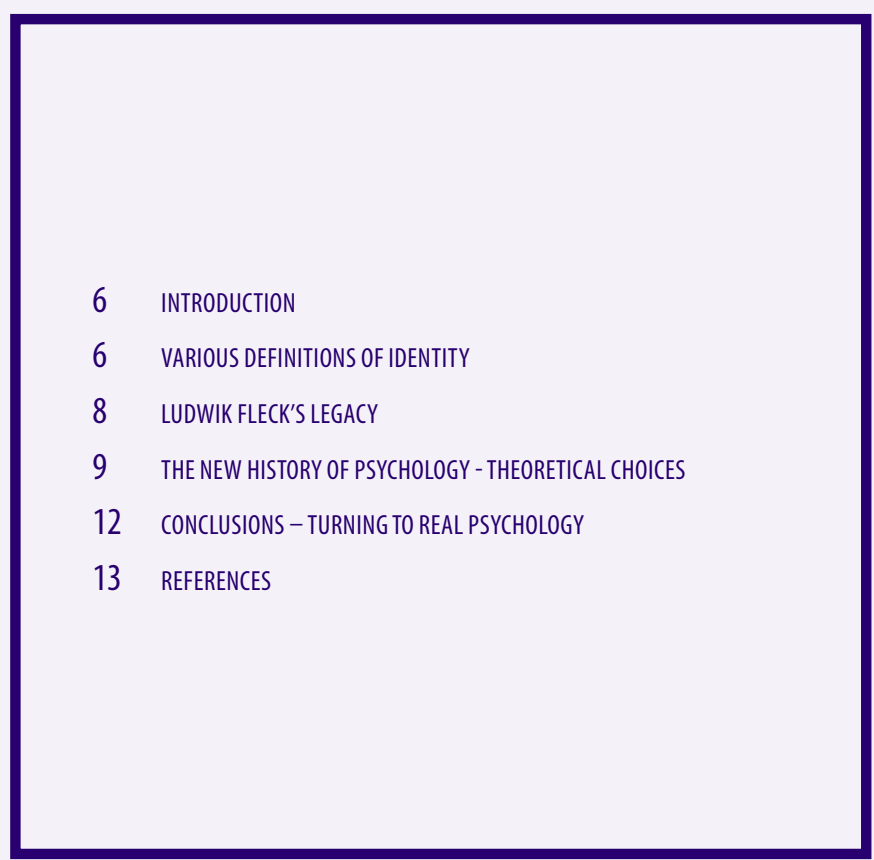




\section{The current state of knowledge remains vague when history is not considered, just as history remains vague without substantive knowledge about the current state.}

Ludwik Fleck (1979)

\section{INTRODUCTION}

\section{VARIOUS DEFINITIONS OF IDENTITY}

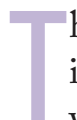

he history of psychology, understood as the study of the history of psychology from its instutionalization (see Danziger, 2013), has been presented selectively and in ways which serve to support the dominant paradigm (Pankalla \& Kilian, 2018). That paradigm has been developed within the mainstream psychology which "refers to the academic field of study as taught and researched in North American and European institutions such as universities" (Teo, 2009, p. 38). Following the transformation of psychology from a philosophical discipline into a natural-scientific discipline in the 19th century, a transformation which was fueled by the struggle for recognition, power and money, some psychology specific topics such as the soul and human experience had to be abandoned. As a consequence, the history of psychology began to parallel the development of technology and mainstream psychology focused on methodology (methodolatry - Bakan, 1967; cult of empiricism Toulmin \& Leary, 1985; methodological imperative - Danziger, 1985; methodologism - Teo, 2005) inadequately creating a reductionistic, atomistic, and mechanistic model of human mental life. Mainstream psychology excludes many locally important concepts such as "ubuntu" from South African psychology (Mkhize, 2004), "the fourth state of consciousness" from Indian psychology (Paranjpe, 1998), issues of liberation psychology from Latin America (Montero \& Christlieb, 2003) or "shin" (the soul) still present in indigenous psychotherapies such as Naikan and Morita in Japan (McVeigh, 2016). Moreover, this approach significantly limits insight into the active role mainstream psychology has played in constructing psychological phenomena such as personality, mental health or disability and the contributions this has had on the wider socio-political order and distribution of power (see Fox, Prilleltensky, \& Austin, 2009).

Principally, mainstream psychology diverts attention from the historical origins and cultural factors of psychological research and provides a misleading impression that psychological studies can be conducted and discussed in isolation. This approach may also lead to strengthening mainstream psychology's claims of scientific objectivity and political neutrality. Furthermore, it may limit our awareness of the fact that psychological research affects reality and has real implications for people's lives.

An awareness of the need for alternate ways of presenting and making the history of psychology, as proposed in this article, corresponds with some elaborations presented by scholars such as Ben Harris or Kurt Danziger. Ben Harris, a professor of psychology at the University of New Hampshire, who works at the intersection of the history of psychology and history of science, clearly states that "methods of historical inquiry are as important to learn as methods of research", "historical accounts themselves are never value-neutral" 
and "once any historical account is written, it can then be used to strengthen a particular interpretation of the past and its implications for the present, that is, it may serve a political purpose" (Harris, 2009, p. 33). Harris explains that: "Dissociated from national and world events, the history of psychology becomes a history of the intellectual discussions within elite groups such as university professors. The discoveries of psychologists are presented as the products of individual inspiration, motivated by a timeless quest for knowledge when being removed from the social world." (Harris, 2009, p. 21). Furthermore, it is important to include three rules of inclusion/exclusion in the history of psychology (Brock, 2006, pp. 3-4). Firstly: "If your work did not have a major impact on the American psychology, however influential it might have been elsewhere, it does not count." Secondly: "If your work had a major impact on American psychology, even though its influence was limited or nonexistent elsewhere, it is an important part of the history of psychology." Thirdly: "Asia, Africa, Latin America, and Oceania do not exist." There are many histories of psychology formed in various places in the world. More importantly, a careless transition and effective implementation of the dominant paradigm in psychology into different countries and societies have been creating irrelevant knowledge and irresponsive practice that is of no real value. This article uses the metaphor of periphery to accentuate the importance of a scientific activity that occurs away from the center. The dependency theories which were developed in the 1960s and 1970s use the terms of "center" and "periphery" to discuss the power and dependency relations between North America and Western Europe (the rich center) and Asia, Africa and South America (the poor periphery; Batur, 2014). This inequality contributed to establishing the superiority of Western knowledge over the marginalised knowledge of the colonized and involved "a large-scale export of psychology as a discipline and profession to the non-Western world" (Staeuble, 2005, p. 184). Regrettably, the history of ideas and people existing on the margins of the favored history of psychology is not included in textbooks nor is it taught in history of psychology courses. Therefore, this article is a call for the study and inclusion of the peripheral histories of psychology in the world's history of psychology - peripheral in a sense of their geopolitical setting as well as alternate knowledge production sources. The response requires sensitivity towards cultural and historical processes as well as a readiness to incorporate the subjective accounts of individuals that participate in the local formation of psychological knowledge.

Most importantly, this call requires us to provide some background to place our analysis in the necessary context. Kurt Danziger, a professor of psychology known for his innovative contributions to the history of psychology, points out that scientific psychology is a domain of constructions and it is essential to acknowledge the fundamentally social nature of psychological knowledge (Danziger, 1990). Moreover, according to Roger Smith (2007), reflexive and mutual process of development should be recognized. As Graham Richards put it: "Psychology itself must be one of the routes by which this process of 'social construction' operates." (Richards, 2010, p. 7). However, psychology has been avoiding these uncomfortable thoughts while fighting for its scientific status. Furthermore, some categories (such as personality or motivation) used by psychologists, do not represent natural categories (Danziger, 1997a). They acquire meanings in cultural-historical contexts and form a sort of implicit knowledge. This knowledge is usually unreflectively accepted and used by researchers in the explicit production of theories and methods. Thus, an investigative practice involves logical and social aspects of research. As noted by Ludwik Fleck (1935/1979), a researcher does not study naked facts but scientific facts that emerge from a peculiar thought style which is produced by members of the collective. Notably, there is also a political dimension that has to be included in the debate, and the influence of the ideology that it produces should not be omitted. 


\section{LUDWIK FLECK'S LEGACY}

Building on the genius of Ludwik Fleck (1896-1961), several crucial points need to be presented not only for the purpose of this paper but also for the advancement of philosophy and historiography of science. Fleck was a Polish-Jewish microbiologist who was reluctantly acknowledged in Kuhn's (1962) work and rediscovered after many years by some peripheral scholars. Importantly, Fleck's work is not only historically significant but also of great value for contemporary meta-scientific debates, including current discussions within the psychological research community. Firstly, Fleck's legacy is an example of science that had been practiced on the margins and generated some unique concepts which remained undiscovered, neglected and de-actualized. The practice of reconstructive historiography is important to realise the power and impact of the processes that determine the construction of historical accounts, the historical embeddedness of scientific theories, and the distribution of produced knowledge.

According to Fleck, cognition is a collective activity that is performed by biased investigators who are influenced by a mental tradition of a thought collective to which they belong (Fleck, 1935/1979). The thought collective is a community of individuals engaged in a process of mutual interaction and transformation of ideas that form a thought style specific to that group, created and socially reinforced in a particular collective mood. Once the thought collective becomes advanced and influential, it is divided into two interconnected and interdependent circles: a small esoteric circle (made of specialists and fully-fledged members of the collective) and a wide exoteric circle (made of their dedicated followers), that communicate intracollectively to corroborate the structure of the thought style and its ideas. Furthermore, every thought style is influenced by elements from earlier thought styles, yet there are always some people who resist this association. It is possible to communicate ideas between thought styles if they share some similarities with each other. Importantly, the intercollective communication of ideas may lead to the development, alteration or a complete change of meanings which is of great epistemological importance. Thought styles begin with the investigation of some proto-ideas, then develop some cognition of reality and scientific facts that support views of that reality. Since the constructions of reality and scientific knowledge change depending on the developments in thought styles, at that point the concept of "truth" is perceived in a historical perspective and a contemporary context. Thus, every concept and idea created within a particular thought style is not invariant in accordance with the idea of incommensurability.

Nowadays, scientists live in very complex societies therefore they belong to many thought collectives. Being aware of thought styles that are associated with specific communities of scholars, is a very desirable approach that ought to form a constant element of everyone's investigative practice. This is especially important, because "the individual within the collective is never, or hardly ever, conscious of the prevailing thought style, which almost always exerts an absolutely compulsive force upon his thinking and with which it is not possible to be at variance." (Fleck, 1935/1979, p. 41). Reconstruction of the thought collective should be performed on two levels: in regards to one's own group of reference and while studying other schools of thinking. These would be preliminary steps before considering types of knowledge that are created within particular thought collectives. The emergence of knowledge is a result of some collective interest in particular phenomena that is supported by certain power relations and embedded in systems of values. Moreover, certain thought collectives and lines of inquiry are pushed aside or underestimated as a consequence of the politics of the dominant thought collectives. Historiographic reconstruction of crypto thought styles would be a beneficial and fascinating way of rediscovering forgotten thought collectives and the neglected areas of knowledge they generated. For psychological science, the consequences of performing this type of scientific activity would be of unpredictable 
impact. Engaging into a dialogue with crypto thought styles present in the history of psychology would reveal hidden knowledge about human beings - knowledge that cannot be produced by other thought styles because it is beyond their vision of reality.

\section{CRITICAL PERSPECTIVE AND THE HISTORY OF PSYCHOLOGY}

Critical thinking towards the dominant paradigms in psychology has been present in several psychological approaches, such as psychoanalysis or humanistic psychology. In recent years, it has taken the shape of a critical psychology which challenges and deals with the limits of the mainstream approach to psychology by performing critical investigations on the basis of new historical inquiry. The critical history of psychology is understood as the study of the histories of psychology that are underprivileged compared with dominant accounts of history of psychology. Its focus is placed on the examination and revision of three interrelated concepts that prevail in mainstream psychology: the restricted level of analysis, the role of ideology, and the false claim of scientific objectivity and political neutrality (see Fox et al., 2009). In essence, psychology's ontological orientation and subject matter - human beings, is viewed and studied in a limited manner operating within the mechanistic model of individual actions, an atomistic approach to study complex phenomena and reductionistic explanations of human mental life. These ontological choices have epistemological and methodological consequences. In mainstream psychology, there is a cult of methodologism (Teo, 2005) which has created a methodological theory of knowledge with no place for the humanistic view of a person and therefore is deprived of its original individuality, subjective complexity and cultural-historical context. Furthermore, this has supported a postulate for value-free and neutral psychological practice which is unaware of its political and ethical foundations and implications. It is not possible to build a scientific status of a discipline and generate meaningful knowledge in the void.

The critical history of psychology would not be the same if it was not for the visionary but unappreciated work of Wilhelm Dilthey (1833-1911). He made a distinction between the natural and human sciences and specified their theoretical tasks. For psychology and history as human sciences, the main task is to understand historical-cultural aspects of human life and the reality of lived experience. According to Dilthey $(1982,1987,2004)$, psychology should be oriented towards understanding, to treating the human experience in its totality as its subject, to study human life in context and to use understanding as a primary research method that comprises elementary forms of understanding, empathy, and hermeneutic understanding. Applying this perspective to the contemporary history of psychology helps to recognize and strengthen the status of the history of psychology as a human science dedicated to reconstructing historical context and applying hermeneutic methods of inquiry in support of psychological knowledge development.

\section{THE NEW HISTORY OF PSYCHOLOGY - THEORETICAL CHOICES}

The historiography of psychology (inspired by the historiography of natural science), which is the study of the writing of history of psychology, has created lots of literature that is affected by many fundamental issues that have been ignored, such as: "we find histories that are no more than literature reviews extended backward in time, we find story telling substituting for history, we find great man hagiography, we find the cult of 'anticipations' and the awarding of good and bad marks on the basis of some current scientific orthodoxy, we find gross insensitivity to historical context, we find the formulation of 'timeless' problems in the 
language of the present, we find the constructions of spurious lines of ancestry, we find the mythology of progress" (Danziger, 1997b, p. 108).

The dominant history of psychology has been created under pressure to provide valuable scholarship in support of the scientific status of mainstream psychology and a respectable place within academia. Notably, the history of psychology was used "as a way of furthering this cause, providing simple storylines that unfolded Psychology's increasing commitment to scientific methods, and what it has accomplished by so doing." (Richards, 2010, p. 4). Historical interpretations are never value-neutral because they are located in specific cognitive perspectives chosen by historians of psychology. For the history of psychology, there are three main distorted ways of presenting historical accounts (see Harris, 2009; Richards, 2010): Whiggish (historical accounts in support of the status quo written by the dominant group), internalist (historical accounts focused on the internal history of psychology) and presentist (historical accounts projecting today's perspective on the past). Some histories of psychology were also presented as a succession of great men while completely ignoring the contextual factors involved in the process. The history of psychology could be organized by presenting its four main domains of interest: psychological topics, psychology as a separate field of study, psychology as an institutionalized discipline, and psychology as profession (see Walsch, Teo, \& Baydala, 2014). However, complementary histories of psychology have appeared on the peripheries of the dominant paradigms, such as: revisionist history (historical accounts challenging the status quo using history), compensatory history (historical accounts focusing on neglected groups - e.g., women and ethnic minorities) or new history of psychology (historical accounts recreating psychological ideas in the social context, including power relations, and the perspectives of different groups). The new history of psychology aimed to be "more contextual, more critical, more archival, more inclusive, and more past-minded" (Furumoto, 1989, p. 30). Thus, the history of psychology should be studied and practiced with the awareness that:

1. "Methods of historical inquiry are as important to learn as methods of research.

2. Historical accounts themselves are never value-neutral. The historian always has to choose some method of data collection and organization over another. The historian also needs to choose an interpretative framework to present an account of the past.

3. Once any historical account is written, it can then be used to strengthen a particular interpretation of the past and its implications for the present, that is, it may serve a political purpose." (Harris, 2009, pp. 33-34).

Kurt Danziger explains that "the way in which we organize a field will determine the way we organize its history" (Danziger, 1990, p. 1). For example, if psychologists are expected to produce scientific activity within the framework of the 19th century physical sciences, they will present the history of psychology as a succession of individual investigators, confirmed hypotheses, developed techniques and accumulated findings. However, that is a very limited approach as psychological knowledge and the historical reconstruction of it are founded on the social activity of scholars in a wider and diverse historical-cultural world. The reconstructive work of a historian of psychology should involve the analysis of the "context of discovery" and the "context of justification." Performing an analysis of the context of discovery means investigating the context of constructing theories, research methods, and results. Analyzing the context of justification is about recognising the community of scholars that constructed and supported the "constructive schemes." Importantly, those schemes provide cognitive frameworks for the interpretations of data but also a set of rules for organizing the data production. More specifically, products of scientific inquiry are constructed by established groups and undergo an acceptance process as not every type of knowledge is equally valued and desired at particular time and in a specific setting. 
Psychological life and psychological inquiry are universal phenomena, however the historiography of psychology has privileged psychological knowledge produced by the dominant centers - with the most influence given to the United States. This negligence towards any peripheral sources of psychological investigation and claims of universal validity led to a one-way flow of the "only legitimate and homogeneous" psychological knowledge to many different locations in Europe, Latin America, Africa, Asia, Australia and Oceania. This colonial-like style of distributing knowledge has been objected to recently by some of the scholars from peripheries. For instance, some Japanese psychologists have realized that they have not produced their own history of psychology but have completely relied on American textbooks and scientific accounts (see Pankalla \& Kilian, 2018). The emergence of indigenous psychologies in various locations has been very inspiring for the history of psychology and for the construction of locally-relevant psychological knowledge. Therefore, "insofar as psychology is regarded as a social project producing locally grounded knowledge, the characteristics of the sides for the production of that knowledge become quite important." (Danziger, 2006, p. 220). Moving towards a polycentric history of psychology reveals the multiplicity of historical data and encourages an investigative practice that is able to deal with rich accounts of psychological knowledge that are relevant to the psychological life of local people.

The previous paragraphs provided an introductory background of the investigative practices in the contemporary history of psychology. Acknowledging and integrating selected approaches offers an original and promising perspective to examine of psychological phenomena and to integrate psychological knowledge within the framework of the history of psychology (see Figure 1).

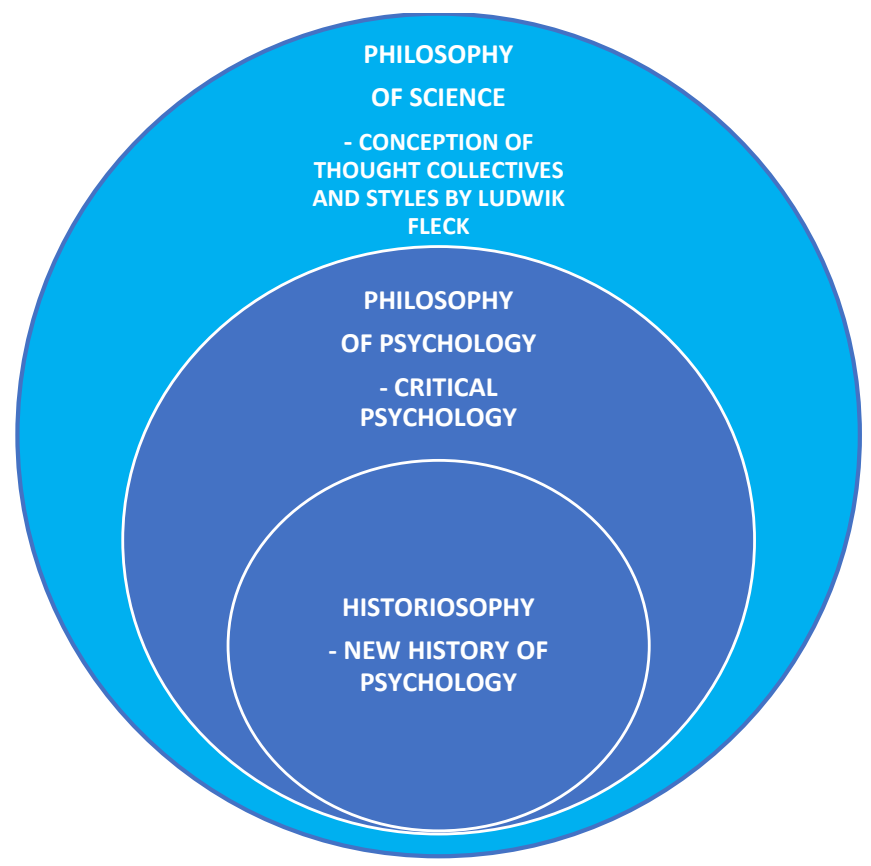

Figure 1. A research perspective for studies in the history of psychology'.

We propose that Figure 1 demonstrates a plausible research perspective and process for conducting studies in the history of psychology. This research perspective is comprised of

1 The perspective was developed by Andrzej Pankalla, Aleksandra Kilian and Konrad Kośnik. 
three interrelated elements: the philosophy of science, the philosophy of psychology and historiosophy, understood as the philosophical interpretation of the course of history of psychology. This research process consists of three stages:

1. Identify thought collectives and the reconstruction of thought styles. Researchers also identify their own thought style and its presuppositions.

2. Apply a critical approach focused on the historical-cultural perspective, including power relations, and value systems. Researchers discover their own value systems.

3. Develop new historical accounts of the studied phenomena, including local context, ideas previously distorted, and excluded groups. Researchers reconstruct and complement current psychological knowledge and advance new studies in the history of psychology.

This methodological perspective is proposed to study unnoticed or marginalised thought styles - crypto thought styles, neglected research areas, complex historical-cultural knowledge, diverse groups of people and phenomena in the history of psychology.

\section{CONCLUSIONS - TURNING TO REAL PSYCHOLOGY}

The aim of real psychology (Pankalla \& Kilian, 2018) is to recognize and reconstruct marginalised lines of inquiry within the framework of a new history of psychology, to promote scholarship that differs from the dominant paradigm in Western psychology, and to remain closely related to the fields of cultural psychology and critical psychology. The main focus is on the unique lifeworld of the human psychic and spiritual life that should be the fundamental subject matter of psychological studies. As noted by Danziger (2013), modern mainstream psychology is a psychology without a soul. Moreover, it is practiced beyond the lifeworld of human experience. The real psychology rediscovers the forgotten and uncomfortable concepts of the soul, life, and experience, and acknowledges their realness and relatedness as well as their historical specificity. The analysis of this fundamental and constant interrelation of life, soul, and experience brings unique and rich accounts of knowledge about a person. This interrelation could be studied by using qualitative research methods based on the understanding that is open to subjective, individual, and distinctive aspects of human experience. Real psychology is inspired by the work of Wilhelm Dilthey (1982) and the German term of "Real-psychologie" which describes the study of the contents of a human soul, occurring connections, and activities.

While looking at the historical aspects of psychological inquiry from the perspective of real psychology, several points should be considered. Firstly, every person and community possess some distinctive historical background, characteristics cultural features, and meanings that convey new insights into the knowledge of locally-created psychological life. Secondly, psychological life is interconnected with historical and cultural frameworks and extends beyond the existing and temporal connections by having a creative and significant impact. Thirdly, no locally produced knowledge about individuals should be omitted in the discourse of scientific psychology. Fourthly, for the practice of psychology to be relevant and compelling, it has to be derived from real world studies and serve the people for whom it is practiced. Fifthly, researchers should be aware of their reality and be reflective about the presuppositions they bring into the analysis of different realities which are never the same and yet are equally intelligible. Considering all these insights allows for psychological investigation to be free from outdated concepts and irrelevant categories as opposed to the current ahistorical approach of identifying universal objects of one unified psychological inquiry. This way of theorising and practicing psychology is fascinated with discovering the 
diverse, fragmented, and cultural-historical reality constructed and used by people in everyday life. As such, this type of psychological inquiry is preoccupied with identifying reality and the meaning it expresses through life experiences in its pursuit of understanding man.

As the history of psychology plays a crucial part in supporting the mainstream paradigm and maintaining the status quo, there is a need for a reflective reconstruction of crypto thought styles present in the whole historiosophy and historiography of psychology. Implicit in such crypto thought styles is the hidden knowledge about a multi-dimensional psychological reality of people and their compound experiences. Notably, this reconstructive work reveals the ethical foundation and system of values of every thought style that is shared by a collective of scholars. Conducting critical studies in the history of psychology requires rediscovering and elaborating on different psychological anthropologies that proceed each thought style. It also requires scholars to form relevant categories and concepts that have been previously and mistakenly applied as organic and to investigate these in any person located in whichever place in the world. Hopefully, this article's perspective on theorizing in the history of psychology will fulfill Danziger's wish that: "By encouraging a genuine historicizing of psychological knowledge it would open up the categories and practices of the discipline to hitherto unthinkable possibilities. Who knows, one day we might even end up with a history of modern psychology that actually contributes to the further development of psychological knowledge.” (Danziger, 2006, p. 223).

\section{A C K N O W LED GEMEN TS}

The authors have no conflict of interest to declare.

\section{REFERENCES}

Bakan, D. (1967). Idolatry in religion and science. In D. Bakan (Ed.), On method: Toward a reconstruction of psychological investigation (pp. 150-159). San Francisco, CA: Jossey-Bass.

Batur S. (2014). Center and periphery. In T. Teo (Ed.), Encyclopedia of critical psychology. New York, NY: Springer. D0I: 10.1007/978-1-4614-5583-7_37

Brock, A. C. (Ed.). (2006). Internationalizing the history of psychology. New York, NY: New York University Press.

Danziger, K. (1985). The methodological imperative in psychology. Philosophy of the Social Sciences, 15, 1-13.D0I: 10.1177/004839318501500101

Danziger, K. (1990). Constructing the subject. Historical origins of psychological research. Cambridge: Cambridge University Press.

Danziger, K. (1997a). Natural kinds, human kinds, and historicity. In W. Maiers (Ed.), Challenges to theoretical psychology (pp. 24-32). Toronto: Captus Press.

Danziger, K. (1997b). The future of psychology's history is not its past: A reply to Rappard. Theory and Psychology, 7(1), 107-111. D0l: 10.1177/0959354397071009

Danziger, K. (2006). Universalism and indigenization in the history of modern psychology. In A. C. Brock (Ed.), Internationalizing the history of psychology (pp. 208-225). New York, NY: New York University Press.

Danziger, K. (2013). Psychology and its history. Theory \& Psychology, 23(6), 829-836. D0l: 10.1177/0959354313502746

Dilthey, W. (1982). Pisma estetyczne. Warszawa: PWN.

Dilthey, W. (1987). 0 istocie filozofii. Warszawa: PWN.

Dilthey, W. (2004). Budowa świata historycznego w naukach humanistycznych. Gdańsk: Wydawnictwo Słowo/Obraz Terytoria.

Fleck, L. (1935/1979). Genesis and development of scientific fact. Chicago, IL: University of Chicago Press.

Fox, D., Prilleltensky, I., \& Austin, S. (Eds.). (2009). Critical psychology: An introduction. Los Angeles-London-New Delhi-Singapore-Washington, DC: Sage.

Furumoto, L. (1989). The new history of psychology. In I. S. Cohen (Ed.), The G. Stanley Hall Lecture Series (Vol. 9, pp. 5-34). Washington, DC: American Psychological Association. D0I: 10.1037/10090-001

Harris, B. (2009). What critical psychologists should know about the history of psychology. In D. Fox, I. Prilleltensky \& S. Austin, (Eds.). Critical psychology: An introduction (pp. 20-35). Los Angeles-London-New Delhi-Singapore-Washington, DC: Sage.

Kuhn, T. S. (1962). The structure of scientific revolutions. Chicago, IL: University of Chicago Press.

McVeigh, B. J. (2016). The history of Japanese psychology: Global perspectives, 1875-1950. London: Bloomsbury Academic. 
Mkhize, N. (2004). Psychology: An African perspective. In D. Hook (Ed.), Critical psychology (pp. 24-52). Lansdowne, South Africa: UCT Press.

Montero, M., \& Christlieb, P. F. (Eds.). (2003). Critical psychology in Latin America [Special issue]. The International Journal of Critical Psychology, 9.

Pankalla, A., \& Kilian, A. (2018). Re-wizja i re-autoryzacja psychologii. Ekspedycja na peryferie - od myśli krytycznej ku psychologii realnej. Czasopismo Psychologiczne, 24(2), 21-35. D01:10.14691/CPPJ.24.1.21

Paranjpe, A. C. (1998). Self and identity in modern psychology and Indian thought. New York, NY: Plenum.

Richards, G. (2010). Putting psychology in its place. Critical historical perspectives. London-New York, NY: Routledge.

Smith, R. (2007). Being human: historical knowledge and the creation of human nature. Manchester: Manchester University Press.

Staeuble, I. (2005). De-centering Western perspectives. In A. C. Brock, J. Louw, \& W. van Hoorn (Eds.), Rediscovering the history of psychology. History and philosophy of psychology (pp. 183-205). Boston, MA: Springer.

Teo, T. (2005). The critique of psychology: From Kant to postcolonial psychology. New York, NY: Springer.

Te0, T. (2009). Philosophical concerns in critical psychology. In D. Fox, I. Prilleltensky, \& S. Austin (Eds.), Critical Psychology: An introduction (pp. 36-53). Los AngelesLondon-New Delhi-Singapore-Washington, DC: Sage.

Toulmin, S., \& Leary, D. E. (1985). The cult of empiricism in psychology, and beyond. In S. Koch \& D. E. Leary (Eds.), A century of psychology as science (pp. 594-617). New York, NY: McGraw-Hill.

Walsch, R. T. G., Te0, T., \& Baydala, A. (2014). A critical history and philosophy of psychology. Diversity of context, thought and practice. Cambridge: Cambridge University Press. 